\title{
IMPACTO DO APELO AO MEDO NAS EMBALAGENS DO CIGARRO: \\ a percepção de fumantes em relação às mensagens de advertência antitabagismo
}

\section{1- José Roberto Mota}

Graduado em Marketing pela Escola de Artes, Ciências e Humanidades da Universidade de São Paulo (USP), Brasil. jrmota@usp.br

\section{2- Cláudia Rosa Acevedo}

Doutora em Administração de Empresas pela Fundação Getúlio Vargas (EAESP/FGV), Brasil.

Professora do curso de Marketing da Escola de Artes, Ciências e Humanidades da Universidade de São Paulo (USP), Brasil. Professora das Faculdades Metropolitanas Unidas (FMU), Brasil. claudiaraac@uol.com.br

http://lattes.cnpq.br/7970180882025380

\section{3- Rejane Alexandrina Domingues Pereira do Prado}

Doutoranda em Administração pela Universidade Nove de Julho (UNINOVE), Brasil. Professora do curso de Administração da Universidade Federal de Uberlândia (UFU), Brasil. rejane@pontal.ufu.br http://lattes.cnpq.br/3932595497052980

\section{4- Julio Araujo Carneiro da Cunha}

Doutor em Administração pela Faculdade de Economia, Administração e Contabilidade da Universidade de São Paulo (FEA/USP), Brasil.

Professor associado do Programa de Mestrado em Administração da Universidade Paulista (UNIP), Brasil. juliocunha@unip.br

http://lattes.cnpq.br/6202822187041175

\section{5- Marli Auxiliadora da Silva}

Doutoranda em Educação pela Universidade Federal de Uberlândia (UFU), Brasil.

Professora do curso de Ciências Contábeis da Universidade Federal de Uberlândia (UFU), Brasil. marli@pontal.ufu.brr

http://lattes.cnpq.br/63896220203420366

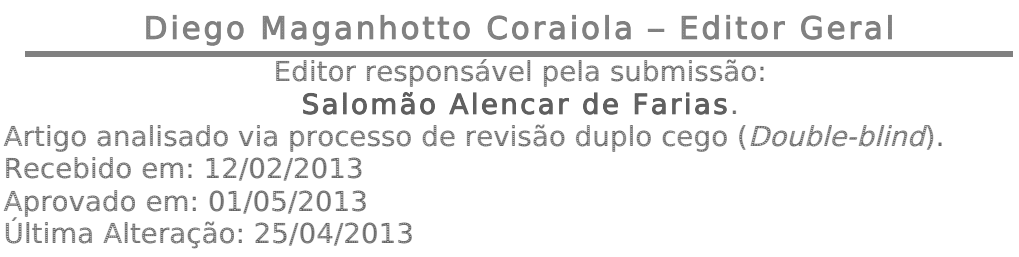

* Contato Principal: Av. Arlindo Béttio, 1000. Ermelino Matarazzo. São Paulo - SP. 03828-000. 


\title{
IMPACTO DO APELO AO MEDO NAS EMBALAGENS DO CIGARRO: A PERCEPÇÃO DE FUMANTES EM RELAÇÃO ÀS MENSAGENS DE ADVERTÊNCIA ANTITABAGISMO
}

\section{RESUMO}

No Brasil, advertências antitabagismo com imagens sanitárias são divulgadas desde 2001 nas embalagens de cigarros sendo o apelo emocional usado como persuasão. Todavia, o medo é uma resposta emocional a uma ameaça e pessoas diferentes têm percepções e reações díspares a esse apelo. Investigou-se, nesse estudo exploratório, as percepções dos fumantes em relação às imagens de advertências antifumo, com apelo ao medo, utilizadas nas embalagens de cigarros considerando-se os temas explorados nas campanhas antitabagismo no Brasil. Os resultados de entrevistas individuais em profundidade com 35 fumantes, homens e mulheres da cidade de São Paulo com idades variáveis entre 20 e 65 anos, indicaram que as mensagens que mais afetam os fumantes são aquelas relacionadas ao câncer e/ou que envolvem crianças. Aproximadamente a metade dos entrevistados afirma que prefere ignorar as imagens que apelam para o medo enquanto quase que a totalidade da amostra confirmou que pensaria em parar de fumar caso vissem mensagens que apontassem os benefícios para tal. Na percepção dos entrevistados as mensagens são mais eficientes quando buscam produzir um conjunto de mensagens positivas e, ainda, confirmou-se que mensagens endossadas por celebridades que não fumam, serviria de maior inspiração para o estímulo à decisão de parar de fumar.

Palavras-chave: Tabaco; Mensagens antitabagismo; Marketing Social; Regulação de tabaco.

\section{FEAR APPEAL IMPACT IN CIGARETTE PACKAGES: SMOKERS' PERCEPTIONS RELATED TO ANTI-} TOBACCO WARNING MESSAGES

\begin{abstract}
In Brazil, antismoking images with health warnings are disclosed in cigarette packages since 2001, being used as the emotional persuasion to smokers. However, fear is an emotional response to a threat and different people may have different perceptions and reactions to this appeal. So, it was investigated in this exploratory study the perceptions of Brazilian smokers in relation to images of warnings related to free smoking existent in the country. These initiatives are based on fear appeal and using warnings at cigarette packages with themes explored in anti-smoking campaigns. The results of in-depth interviews with 35 smokers, men and women from the city of São Paulo, with ages ranging from 20 to 65 , indicated that the messages that will affect smokers are those related to cancer and/or involving children. Approximately half of respondents say they prefer to ignore the images that appeal to fear while almost the entire sample confirmed that would think about quitting if they could notice messages that pointed to such benefits. Interviewees perceived the messages are most effective when they intent to produce a set of positive messages and also confirmed that messages endorsed by celebrities who do not smoke would serve as inspiration for the greater encouragement to the decision to smoking stoppage.
\end{abstract}

Keywords: Tobacco; Anti-smoking messages; Social Marketing; Regulation of tobacco. 
José Roberto Mota, Cláudia Rosa Acevedo, Rejane Alexandrina Domingues Pereira do Prado, Julio Araujo Carneiro da Cunha, Marli Auxiliadora da Silva

\section{Introdução}

Os malefícios causados pelo uso do cigarro são amplamente divulgados na maioria dos países e, mesmo com a ampla divulgação sobre o tema, existe em todo o mundo 1,2 bilhão de fumantes, sendo que o consumo de cigarro ainda é crescente (Hammond, 2008). Aproximadamente $12 \%$ da população feminina e $47 \%$ da população masculina mundial fumam (Iglesias, Jha, Pinto, Silva, \& Godinho, 2007). No Brasil, dados do Instituto Brasileiro de Geografia e Estatística (IBGE), em 2008, enumeravam 25 milhões de fumantes (IBGE, 2008). A preocupação com a incidência de fumantes se refletiu no meio acadêmico, de forma que os artigos científicos que abordam o tema têm apresentado crescimento a cada década desde o início do século passado (Spink, Lisboa \& Ribeiro, 2009).

O tabagismo é um hábito que ocasiona efeitos colaterais para a saúde do fumante e os malefícios desse hábito levam, inclusive, ao óbito. Anualmente, são registrados cerca de seis milhões de óbitos em decorrência de doenças causados pelo tabaco, sendo $10 \%$ desses óbitos de fumantes passivos (World Health Organization, 2011). Citam-se como as principais doenças causadas pelo consumo do cigarro os enfisemas, cânceres, infartos e várias outras deficiências cardiovasculares (Cavalcante, 2007). Além das adversidades relacionadas à saúde e à qualidade de vida de fumantes ativos e passivos, o tabagismo se caracteriza também como problema de saúde pública (Spink et al, 2009) e geram, por conseguinte, custos ao sistema de saúde com prejuízos aos cofres públicos para o tratamento de pessoas que desenvolvem doenças oriundas do tabagismo (MacKay \& Eriksen, 2002). Tangari, Burton, Andrews e Netmeyer (2007) afirmam que os custos para tratar essas doenças, em todo o mundo, podem chegar a US\$160 bilhões anuais, pois são gastos US\$75 bilhões em custos médicos diretos e aproximadamente US\$90 bilhões em perda de produtividade.

Uma das estratégias do poder público para a tentativa de redução do número de fumantes e, consequentemente, dos gastos com os tratamentos médicos e perda de produtividade foi a criação de campanhas publicitárias, tanto por órgãos governamentais, lideradas nacionalmente pelo Sistema único de Saúde (SUS) (Santos, 2011) como aquelas ações de caráter regional, como é o caso, por exemplo, da lei municipal da cidade de São Paulo (Souza \& Dias, 2011) e até outras experiências estrangeiras que se apoiam em motes publicitários e divulgação de mensagens antitabagistas vêm se mostrando válidas na redução da quantidade de fumantes (Wakefield, Durkin, Spitall, Siahpush, Scollo, Simpson, Chapman, White \& Hill, 2008; Terry-McElrath, Emery, Wakefield, O'Malley, Szczypka \& Johnston, 2011; Malone, Grundy \& Bero, 2012).

Os resultados positivos dessas campanhas são comprovados mesmo diante de esforços contrários no sentido de agregar valor aos produtos provenientes do marketing elaborado pela indústria tabagista (Farrelly, Davis, Duke \& Messeri, 2009). Entretanto, ainda que as campanhas antitabagismo sejam passíveis de resultados positivos, existem estudos que apontam formas de atribuir-lhes maior efetividade (Renovato, Bagnato, Missio, Murback, Cruz \& Bassinello, 2009) contribuindo para a melhoria dos efeitos gerados pelas campanhas antitabagismo.

Uma das estratégias adotadas nas campanhas antitabagismo é a inserção de advertências e imagens de impacto nas embalagens de cigarros alertando e mostrando visualmente ao fumante os impactos negativos decorrentes do tabaco, visto que a embalagem é considerada um componente importante na estratégia de marketing de bens de consumo, pois ajuda a estabelecer identidade de marca em mercados competitivos e serve como uma forma efetiva de promoção no ponto de venda e durante todo o tempo de uso do produto (Shapiro, Perreault \& McCarthy, 1999).

Estudo realizado por Wakefield (2011) mostra que a percepção da marca apresentada na embalagem do cigarro tem o poder de oferecer uma experiência mais agradável ao fumante. De forma análoga outros autores afirmam que a embalagem do cigarro pode promover, ou não, a experiência do fumante e reforçar seus comportamentos voltados ao ato de fumar (Hoek, Wong, Gendall, Louviere \& Cong, 2011). O que o fumante vê na embalagem tem efeito direto na sua experiência de fumar.

Pesquisas realizadas a respeito das campanhas antifumo em embalagens de cigarros apresentaram características em comum em suas respostas: 1) As advertências nos maços de cigarro estão entre as comunicações para a saúde com maior eficiência e maior custo-benefício; 2) A advertência sobre a saúde tem alto grau de conscientização e visibilidade entre os não fumantes e os jovens; 3) Textos obscuros de advertência têm pouco impacto; 4) Advertências com imagens destacadas podem aumentar os conhecimentos sobre a saúde, a motivação para parar de fumar e o comportamento de diminuição do uso; 5) Advertência com imagens são especialmente importantes para atingir fumantes com pouca instrução e crianças; 6) Mensagens que ressaltam os riscos para a saúde de forma chocante e com apelo emocional são mais eficientes; 7) Advertência com imagens possuem credibilidade e alto nível de apoio por parte do público (Hammond, 2008).

A partir dessas constatações Hoek et al (2011) asseguram que as embalagens de cigarro contendo mais espaço para as propagandas antitabagismo e imagens de advertência têm maior impacto e fazem com que o ato de fumar fique menos atrativo ao fumante (Hammond, 2008).

No Brasil, conforme aponta Cavalcante (2007), o impacto das campanhas antitabagismo iniciou-se em 1988, quando foi obrigatória a inserção de frases de advertência na lateral das embalagens como, por exemplo, “o ministério da saúde adverte: fumar é prejudicial à saúde". Posteriormente, outras frases de maior impacto, remetendo a doenças mais graves, foram elaboradas. No entanto, esses alertas eram frases simples e diretas, num espaço restrito à lateral e escrito de forma a não chamar a atenção. Essa falta de visibilidade se justificou principalmente porque o próprio fabricante, receoso da redução do consumo de seu produto, era quem decidia 
Impacto do apelo ao medo nas embalagens do cigarro: a percepção de fumantes em relação às mensagens de advertência antitabagismo

como escrever as advertências num acordo entre as companhias de tabaco e o governo nacional. No entanto os efeitos dessas iniciativas não foram satisfatórios e, por isso, a evolução se deu com a inserção de imagens nas embalagens de cigarros demonstrando as consequências negativas para a saúde causadas pelo uso do fumo (Cavalcante, 2007).

Diante do exposto esse estudo teve como objetivo identificar a percepção de fumantes em relação às imagens antitabagismo nas embalagens de cigarro e verificar se a mensagem pretendida com a exposição dessas imagens, cujo apelo emocional remete ao medo, tem efeito direto na experiência do fumante. Os resultados desse estudo poderão, ainda, resultar em informações a serem usadas por políticas públicas em campanhas antifumo.

Expõe-se, na sequência, o arcabouço teórico que abrange uma revisão sobre o marketing social e apresenta o atual estágio do conhecimento sobre as estratégias antifumo em embalagens de cigarros. Apresenta-se, também, uma seção com as escolhas e procedimentos metodológicos, seguida pelos resultados, discussões e conclusões da pesquisa.

\section{Revisão de Literatura}

A revisão da literatura está organizada em dois blocos. O primeiro apresenta alguns conceitos de marketing social, visto sua aplicação ser uma das estratégias de intervenção social utilizada no mundo todo para esclarecer os malefícios e reduzir o hábito de fumar. Em seguida são apresentadas as estratégias antifumo em embalagens de cigarro utilizadas no Brasil e os resultados de pesquisas sobre as técnicas de persuasão nas campanhas antitabagismo.

\subsection{Marketing Social}

Até meados do século XX, duas fases caracterizaram a disciplina de Marketing voltada à perspectiva do consumidor (Lefebvre \& Flora, 1988). A primeira embasou-se no tradicional Marketing Comercial, cuja mentalidade orientadora sustentava-se nos conceitos de produção, ou seja, no aumento de produção e na redução de custos. Os autores alegam que a orientação migrou para as vendas, visto que o aumento das vendas e lucros tornaram-se o objetivo principal dos profissionais da área até meados do século XX. Contudo, a partir da década de 1950, novos conceitos aplicados ao Marketing passaram a ganhar proporções. Diante de uma sociedade que se voltara a preocupações relacionadas à qualidade de vida dos consumidores emergiram novos padrões de comportamento e despertou a atenção para o marketing social (Wiebe, 1952).

A expressão Marketing Social foi primeiramente utilizada por Kotler e Zaltman, que em 1971 estudavam aplicações do marketing que contribuíssem para a busca e o encaminhamento de soluções para as diversas questões sociais. Os autores definiram o marketing social como o processo de criação, implantação e controle de programas usados para influenciar a aceitabilidade das ideias sociais envolvendo considerações relativas ao planejamento, preço, comunicação, distribuição e pesquisa de marketing (Kotler \& Zaltman, 1971).

Novos estudos aprimoraram o conceito de Marketing Social (Andreasen, 1994; 1995; 2002). Para este autor o marketing social é a adaptação das tecnologias do marketing comercial para programas destinados a influenciar o comportamento voluntário de públicos-alvo e promover mudanças visando o bem-estar pessoal e de toda a sociedade. As estratégias do Marketing Social buscam a mudança de atitudes, crenças e comportamentos de indivíduos ou organizações para um benefício social e, por conseguinte, a própria mudança da sociedade.

Nesse sentido, o Marketing Social visa garantir o bem-estar pessoal e social, por meio da melhoria da qualidade de vida obtida com a transformação social oriunda da implantação de inovações sociais (adoção de conhecimentos, atitudes e práticas individuais e coletivas). Diferentemente do mercado assistencialista e do mercado comercial, no mercado social quem ganha os benefícios, na relação de troca, não é o agente de mudanças (produtor) e sim a sociedade, uma vez que os benefícios são coletivos (Fontes, 2008). Trata-se de uma orientação ampliada para a coletividade social.

O uso de estratégias de Marketing Social é apropriado ao desenvolvimento e implantação de estratégias para iniciar a mudança de comportamento (Belch, 1982; Hassan, Walsh, Shiu, Hastings \& Harris, 2007). As intervenções sociais de diferentes tipos podem ser eficazes e trabalhadas com diferentes grupos, tais como jovens, adultos, minorias étnicas e grupos desfavorecidos e em vários contextos, entre eles, escolas, locais de trabalho, igrejas, supermercados e meios de comunicação (O'Connor \& Lundstrom, 2011). Por isso, o Marketing Social, diferentemente das abordagens tradicionais, pode contribuir para a redução do consumo a fim de promover mudanças para estilos de vida mais sustentáveis (Peattie \& Peattie, 2009).

A abordagem comportamental do Marketing Social permite sua aplicação para promoção de causas sociais e políticas públicas (Walsh, Rudd, Moeykens \& Moloney, 1993), sendo frequentemente aplicado em casos de promoção à saúde e prevenção de doenças (Ling, Franklin, Lindsteadt \& Gearon, 1992; Winett, 1995). Ao ser aplicado junto aos determinantes de um comportamento social de risco à saúde das pessoas, criam-se contextos de intervenção que podem auxiliar em campanhas de política pública da área (Hoek \& Jones, 2011 ). Dessa forma, ações de Marketing Social auxiliam no planejamento, foco, refinamento e implantação de programas sociais no âmbito da saúde, além de servir como contra-argumentação para iniciativas publicitárias das organizações utilitaristas que podem trazer consequências pouco saudáveis (Petersen, 2008). 
Programas antitabagistas comumente se apoiam em estratégias oriundas do Marketing Social para aplicação em suas campanhas, dada sua sustentação social e orientação ao consumidor (Manoff, 1985) de forma a estimular a mudança no comportamento dos fumantes. Uma das ferramentas dessas campanhas é a inserção de imagens e textos de impacto nas embalagens de cigarros a fim de provocarem reflexão nos usuários. Assim, as campanhas antifumo de cunho social que se utilizam de imagens são mais propensas à aceitação visto os impulsos visuais que valorizam o comportamento de não consumo (Gallopel-Morvan, Gabriel, Gall-Ely, Rieunier \& Urien, 2011).

\subsection{Estratégias Antifumo em Embalagens de Cigarro e o Apelo ao Medo}

O tabagismo é considerado uma questão crítica para a saúde pública, pois aproximadamente $50 \%$ dos fumantes assíduos quando adultos morrem de alguma doença relacionada ao hábito de fumar (Tangari et al, 2007). Por essa razão campanhas de marketing social que visem o consumo do cigarro e suas variações podem contribuir para a mudança de comportamento e hábitos desse público.

As iniciativas para o combate ao uso do fumo estão mais presentes em países desenvolvidos oferecendo maior aparato legal e apelo às campanhas de combate ao tabagismo. Em países em desenvolvimento a falta de políticas antifumo tem proporcionado um crescimento no consumo do cigarro devido à maior liberalidade de ações por parte da indústria do fumo (MacKay \& Crofton, 1996).

A propaganda de cigarros passou por uma série de restrições, principalmente em termos de horário e linguagem, antes de ser definitivamente banida da mídia brasileira (Toledo \& Caigawa, 2003). As restrições modificaram a maneira como algumas marcas passaram a se comunicar com o público. O aumento das restrições gerou inquietações na indústria e nos setores envolvidos com a propaganda do cigarro, visto que as restrições e proibições legais tornaram-se o foco do Ministério da Saúde que, por meio da mídia, reforçou publicamente este valor.

Mensagens de advertência sobre saúde dos fumantes foram implantadas nas embalagens de cigarros em campanhas de combate ao tabagismo desde 1971, quando 77 países adicionaram algum tipo de mensagem sobre saúde nas embalagens dos produtos derivados do tabaco (World Bank, 1999). Hoje, essa é uma das estratégias mais utilizadas por órgãos públicos para explicitar a manipulação sobre os malefícios à saúde do fumante que, geralmente, são negligenciados pela indústria do tabaco. De fato, essa estratégia vem se demonstrando eficiente à medida que os estudos que comprovam que exposições de imagens impactantes associadas a mensagens de advertência são eficazes no combate ao tabagismo (Balbach \& Glantz, 1998; Strahan, White, Fong, Fabrigar, Zanna \& Cameron, 2002; Hammond, 2008; Ramuski, 2009; Sabbane, Lowrey \& Chebat, 2009; Gallopel-Morvan et al, 2011; Hoek et al, 2011; Terry-McElrath et al, 2011).

Aliadas às campanhas antitabagismo outras iniciativas em relação à contenção do consumo do cigarro e ao esclarecimento à sociedade sobre seus malefícios se confirmam na legislação brasileira. A Lei no 9.294 , de 15 de julho de 1996, proibiu o uso de cigarro em recinto coletivo, privado ou público. Em novembro de 20110 Senado aprovou o Projeto de Lei de Conversão (PLV) no 292011, originário da Medida Provisória no 540201 que prevê, entre outras coisas, o aumento da tributação sobre a comercialização do cigarro, a extinção dos fumódromos e o aumento do preço de venda do produto (INCA, 2003).

A restrição à propaganda de cigarro é, no entanto, uma das mais importantes ações de controle do tabagismo adotadas no Brasil nos últimos dez anos. A proibição às propagandas nos pontos internos de venda, a partir de dezembro de 2000, foi extensiva ao patrocínio de eventos culturais e esportivos pelas companhias de tabaco. Outra importante ação foi a inclusão de advertências sanitárias com fotos impactantes nas embalagens de produtos de tabaco a partir de 2001 (INCA, 2003; Cavalcante, 2007; Ruas \& Estellita-Lins, 2011).

Ruas e Estellita-Lins (2011) afirmam que o Canadá e o Brasil foram os países pioneiros no uso efetivo das advertências, em 2000 e 2001, respectivamente, com legislação própria e, determinando a impressão de advertências acompanhadas de imagens que passaram a ocupar metade da frente e do verso das embalagens de produtos derivados do tabaco. No Brasil, em 2008, novas imagens de advertência foram lançadas pelo Ministério da Saúde para a campanha antifumo visto que a atualização e rotatividade dessas imagens dão maior eficácia para as campanhas (Gallopel-Morvan et al, 2011). Com essas mensagens o governo brasileiro busca conscientizar os cidadãos em relação às consequências e efeitos adversos à saúde do fumante. A Figura 1 , exemplifica algumas formas de mensagens com uso de imagens sanitárias nas embalagens de cigarro utilizadas em diversos países do mundo.

Para Gallopel-Morvan et al (2011) o uso de imagens impactantes em associação com mensagens de advertência é comprovadamente mais eficiente que a imagem isolada. A utilização dessa estratégia em campanhas antitabagistas com imagens sanitárias nas embalagens de cigarro faz parte de uma técnica que emprega o apelo ao medo e ao terror como forma de persuasão para influenciar a mudança de percepção (Shehryar \& Hunt, 2005). Conforme definido por Milne, Sheeran e Orbel (2000), a propaganda com apelo ao medo é um comunicado informativo sobre uma ameaça ao bem estar pessoal.

Pesquisas em torno do que geralmente é chamado de "apelo ao medo" tem predominantemente examinado seu efeito persuasivo nas comunicações ao consumidor. Segundo La Tour e Rotfeld (1997), mesmo após cinco décadas de estudos, os dados publicados e as teorias desenvolvidas ainda são confusas. Os autores 
Impacto do apelo ao medo nas embalagens do cigarro: a percepção de fumantes em relação às mensagens de advertência antitabagismo

afirmam que desde a Segunda Guerra Mundial, muitas pesquisas têm buscado estudar quais os tipos de ameaças são mais persuasivas. A discussão central sobre esse tema é que o medo é uma resposta emocional a uma ameaça e pessoas diferentes têm reações díspares ao medo. Ou seja, nenhuma ameaça causa reação idêntica em todas as pessoas.

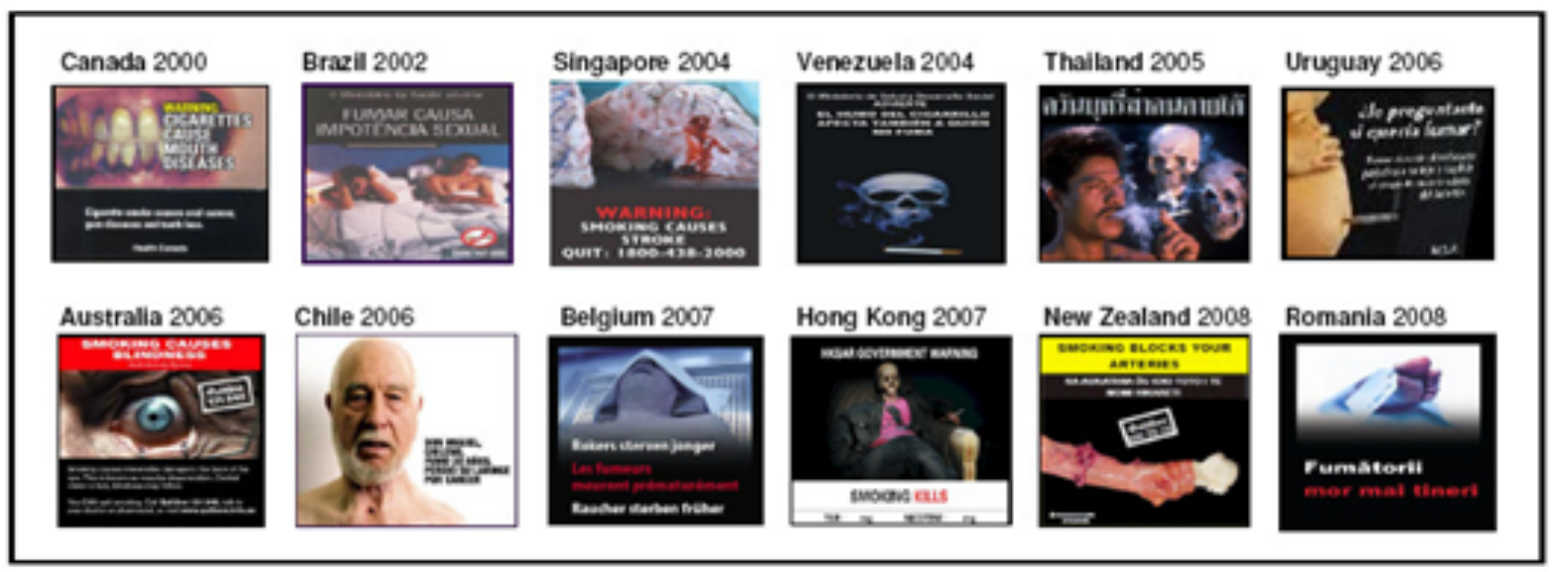

Figura 1 - Imagens de advertências sanitárias usadas nas embalagens de cigarro Fonte: http://www.tobaccolabels.ca/labelima

Esse apelo ao terror se reforça quando se percebe que as mensagens não apresentam alternativas que podem ser tomadas para evitar ameaças à saúde (Milne, Sheeran \& Orbel, 2000). Há, inclusive, uma linha de pensamento que acredita que essas campanhas são consideradas limitadas por serem parciais e porque as campanhas em embalagens de cigarros trazem imagens reducionistas e sem o aprofundamento da dimensão política envolvida no tema. Não se pode afirmar que as campanhas sanitárias em embalagens de cigarros são completas e abrangentes, podendo ser, portanto, enviesadas (Renovato et al, 2009).

Em relação à intensidade de medo aplicado às campanhas antifumo, os resultados das pesquisas não são consensuais. De um lado, um grupo de estudiosos defende que campanhas antitabagismo com mensagens carregadas de intensidade emocional têm maior eficácia que aquelas sem o mesmo apelo (Biener, Ji, Gilpin \& Albers, 2004; Biener, Wakefield, Shiner \& Siegel, 2008). Por sua vez, outra linha de pensamento entende que o apelo ao medo moderado parece ser mais efetivo para a mudança de comportamento, de forma que um apelo fraco pode não surtir resultado, enquanto um apelo forte pode ser tão apavorante ao receptor que o leva a evitá-lo ou ignorá-lo (De Bruin, 2006). Independente desse impasse no campo do conhecimento o medo despertado por uma comunicação com ameaça não tem o poder de mudar, diretamente, um comportamento, mas é a avaliação cognitiva da informação que faz a intermediação da persuasão (Rodgers, 1983).

Pesquisas ainda demonstram que a resposta do indivíduo às mensagens que usam do apelo ao medo depende do envolvimento da pessoa com o assunto em questão. Pessoas com alto grau de envolvimento, ou seja, que percebem, entendem e/ou conhecem o risco do comportamento inadequado serão mais persuadidas pela mensagem, todavia, aqueles que possuem um baixo envolvimento com o tema da mensagem, ou seja, desconhecem o assunto e suas consequências tendem a ignorar a mensagem (Maheswaran \& Meyers-Levy, 1990).

Pelsmacker, Cauberghe e Dens (2011) entendem que campanhas que envolvem imagens gráficas que remetem ao medo como ferramenta de persuasão são mais eficientes quando os problemas (prejuízos à saúde) são menos familiares pelo público-alvo da campanha. Assim, estratégia de Marketing Social com apelo às imagens pode ser mais apropriada para os jovens que, potencialmente, têm menos conhecimentos sobre os males que o fumo pode acarretar. Considerando o exemplo dos jovens fumantes, Hastings, Stead e Webb (2004) afirmam que o uso do medo pode não ser a melhor alternativa para o convencimento dos jovens e que o uso de humor e ironias pós-modernas podem ser mais efetivas para esse público. Complementarmente, Ramuski (2009) entende que as campanhas de embalagens de cigarros só têm efeitos sobre os jovens quando eles as consideram importantes e, assim, memorizam as imagens. Todavia, poucas imagens fazem referência ao universo jovem, o que dificulta a memorização das imagens e do impacto das campanhas (Ramuski, 2009).

Ruas e Estellita-Lins (2011) e Cotter, Perez, Dunlop, Hung, Dessaix e Bishop (2010) asseguram que as campanhas antitabagismo, em especial, as que apresentam imagens impactantes em embalagens de cigarros, devem ter figuras capazes de serem memorizadas pelo seu público-alvo e são mais eficientes quando adaptadas e direcionadas a cada público-alvo. Focalizar as percepções relevantes para cada público alvo (Strahan et al, 2002) é essencial, já que diferentes mensagens são compreendidas de forma específica por cada segmento da população, por exemplo, aqueles que fumam versus aqueles que estão na iminência de fumar; adolescentes versus adultos. É importante não apenas identificar quais percepções e crenças são relevantes para determinado grupo, mas também descobrir quais razões contribuem para a formação das crenças a favor ou contra o fumo. Nesse aspecto, Tangari et al (2007) identificaram que jovens adultos têm fortes crenças a 
respeito do fumo passivo e são mais propensos a pararem de fumar. Isso sugere um mercado potencialmente receptivo para campanhas antifumo.

A figura 2, na sequência, sintetiza a relação entre as mensagens de apelo ao medo, o grau de envolvimento sobre o tema, a percepção e a experiência do fumante.

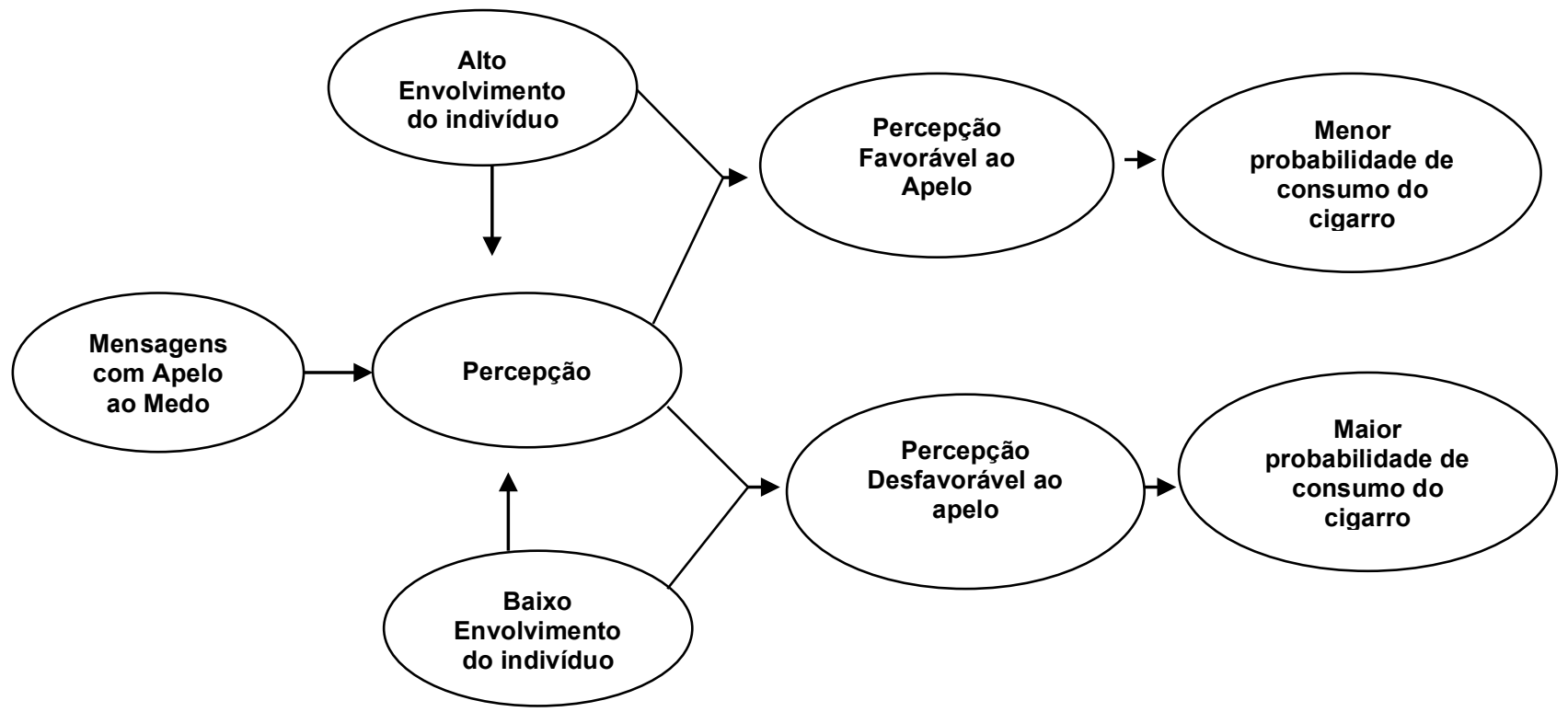

Figura 2 - Percepção sobre as mensagens de apelo ao medo Fonte: Elaborada pelos autores

\section{Procedimentos Metodológicos}

O presente estudo identificou a percepção de fumantes em relação às imagens antitabagismo nas embalagens de cigarro verificando, ainda, se a mensagem pretendida com a exposição dessas imagens tem efeito direto na experiência do fumante, especialmente ao considerar-se o apelo ao medo usado como estratégia nas campanhas de advertência. A pesquisa caracteriza-se como exploratória com abordagem qualitativa no momento em que se classificam as categorias de percepção das mensagens antitabagismo. Posteriormente, ao se agrupar as respostas e falas coletadas dentro das categorias definidas tem-se um estudo qualitativo de natureza descritiva.

\subsection{Coleta de Dados}

Na pesquisa de campo, utilizou-se a técnica de amostragem não probabilística tipo 'bola de neve', do inglês snow ball. A amostragem 'bola de neve' é muito útil quando há um grau de dificuldade em identificar entrevistados em potencial. Após se identificar alguns entrevistados pede-se a esses que indiquem outros indivíduos que possam, também, ser entrevistados (Rea \& Parker, 2000). Por conveniência dos pesquisadores escolheu-se um grupo inicial de entrevistados, visto que esses faziam parte de suas redes de relacionamentos e, a partir de então, pediu-se a esses indivíduos que indicassem outros que tivessem o hábito de fumar e assim sucessivamente.

Dessa forma, cada uma das entrevistas foi conduzida num ambiente particular, variando o ambiente da abordagem presencial realizada entre os locais de trabalho, residência e locais de estudo dos entrevistados. Cada uma das entrevistas seguiu um protocolo no qual o roteiro de perguntas era seguido juntamente com a apresentação dos cartazes de apoio.

Utilizou-se a entrevista individual em profundidade como técnica de coleta de dados. As entrevistas foram realizadas até que houvesse redundância nas narrativas, pois estas não mais contribuíam para informações adicionais (Taylor \& Bogdan, 1998).

Utilizaram-se os critérios de classe social desenvolvidos pela Associação Brasileira de Empresas de Pesquisa (Abep). A divisão da população brasileira em classes socioeconômicas é baseada no Critério de Classificação Econômica Brasil, feito pela Abep. Essa classificação surgiu em 1997 para medir o poder aquisitivo das pessoas, avaliando os bens da família e o grau de escolaridade do chefe da casa. Na prática, itens possuídos pela família valem pontos e definem a que classe ela pertence. Essa metodologia difere daquela usada pelo Censo, do IBGE, que não define classe, só renda, e mesmo assim, corre-se o risco de distorção dos dados devido a informações falsas sobre quanto se ganha efetivamente (Salla, 2011).

O instrumento para coleta de dados constituiu-se em um roteiro com perguntas abertas. As questões que fizeram parte do roteiro de entrevistas são apresentadas na Figura 3. 
Impacto do apelo ao medo nas embalagens do cigarro: a percepção de fumantes em relação às mensagens de advertência antitabagismo

a) Você se preocupa com a saúde?

b) Você costuma ler reportagens ou artigos sobre saúde?

c) Você costuma prestar atenção nas imagens dos maços de cigarros?

d) Você observa os detalhes da imagem?

e) Você comenta com outras pessoas sobre as imagens nos maços de cigarros?

f) O que você sente ao ver as imagens de advertência (mostrar imagens) que estão nos maços de cigarros?

g) Estas imagens o afetam de alguma forma?

h) As imagens fazem você pensar em parar de fumar?

i) Quais destas imagens mais te impressionam?

j) Dos temas abordados pelas campanhas (câncer, problemas respiratórios, impotência sexual etc.) qual deles mais preocupa os fumantes em geral?

k) Dos temas abordados pela campanha qual mais o preocupa?

1) O que você acha dessas campanhas?

Figura 3 - Roteiro de questões apresentadas aos entrevistados

Fonte: Elaborado pelos autores.

Utilizou-se como recurso nas entrevistas as imagens antitabagismo apresentadas em embalagens de cigarros que fazem parte das campanhas do governo brasileiro. As imagens utilizadas, evidenciadas na Figura 4, só foram apresentadas aos entrevistados a partir da questão ' $f$ ' e elas podiam ser manuseadas pelo entrevistado se o mesmo sentisse necessidade. Ou seja, essas imagens foram apresentadas em cartazes com as imagens ampliadas, os quais ficaram em frente aos entrevistados e os mesmos podiam olhar e analisar as mensagens o quanto quisessem durante a entrevista.

As entrevistas foram gravadas e transcritas por meio da técnica de análise de conteúdo. A análise de conteúdo presta-se tanto aos fins exploratórios quanto aos de verificação, confirmando ou não proposições e evidências (Bardin, 1997). Nesse estudo utilizou-se a análise de conteúdo com o fim de medir a clareza das mensagens e identificar como as intenções, características e apelos de comunicadores foram percebidos pelos entrevistados (Martins \& Theóphilo, 2007). Seguiram-se as recomendações de Spink (1998) para se estruturar o método de análise de conteúdo e interpretação dos falas coletadas.

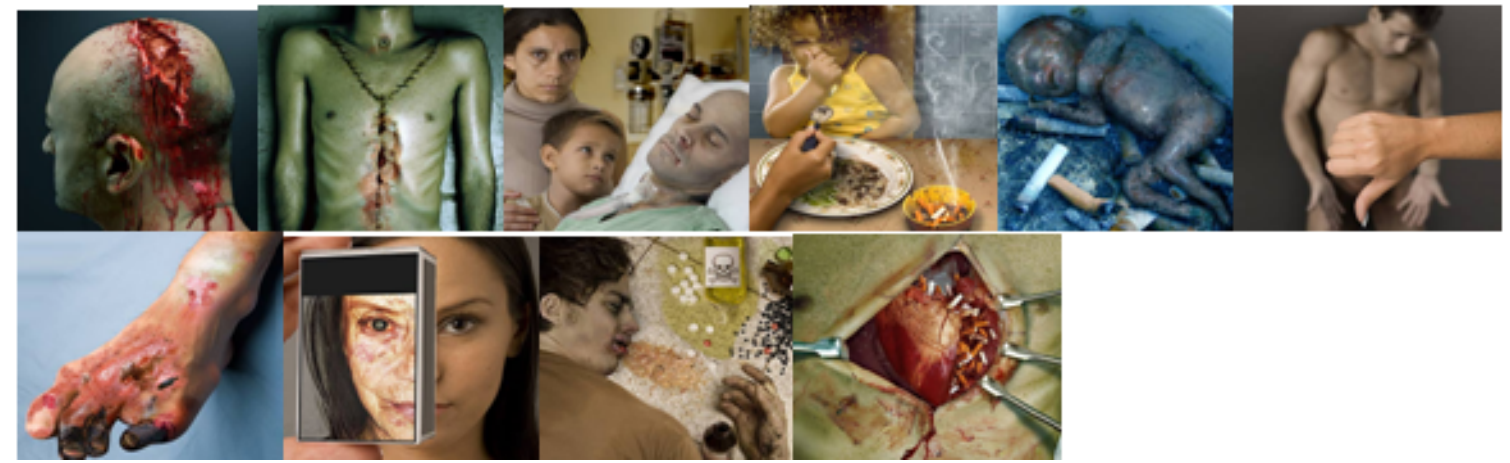

Figura 4 - Imagens de advertências em embalagens de cigarros utilizadas nas entrevistas Fonte: ALETP, 2008.

\subsection{Análise de Dados}

A análise foi iniciada com uma leitura flutuante do material, com o objetivo de identificar os conceitos que poderiam emergir das narrativas. Bardin (1997) assegura que a leitura flutuante consiste em estabelecer o contato com os documentos a fim de analisar e conhecer o texto, deixando-se invadir por impressões e orientações. É na leitura flutuante que surgem hipóteses ou questões norteadoras, em função de teorias conhecidas.

Em uma etapa subsequente, as respostas foram mapeadas utilizando-se algumas dimensões analíticas selecionadas como as palavras 'chocantes', 'amedrontadoras', 'imagens muito feias', 'imagens falsas' e frases ditas pelos entrevistados. Na sequência, a partir de uma análise inferencial dos quadros de referência, criados a partir do estabelecimento do critério de repetição das palavras selecionadas, foram analisados os resultados. Resultante da análise das entrevistas, mapeamento das referências (conceitos) relativos às imagens e associação de ideias foram definidas três dimensões analíticas para se estruturar os resultados. São elas: a) Comportamento dos entrevistados frente as imagens; b) Efeito das imagens sobre os entrevistados; c) A percepção dos entrevistados sobre os tipos de argumentos para convencer o fumante a parar de fumar permitindo-se elencar 9 (nove) categorias de percepção sobre as imagens de advertência antitabagismo divulgadas nas embalagens de cigarro.

\section{Discussão dos Resultados}

Os resultados das entrevistas são relatados em três blocos distintos, segundo as três dimensões analíticas - comportamento, efeito e tipos de argumentos - que resultaram nas categorias descritas na Figura 5. 
José Roberto Mota, Cláudia Rosa Acevedo, Rejane Alexandrina Domingues Pereira do Prado, Julio Araujo Carneiro da Cunha, Marli Auxiliadora da Silva

\begin{tabular}{|c|c|}
\hline Dimensões analíticas & Categorias de percepção \\
\hline 1. Comportamento & $\begin{array}{l}\text { a) O ato de fumar traz riscos à saúde. } \\
\text { b) As mensagens são ignoradas porque os fumantes preferem não olhá-las. } \\
\text { c) As imagens são menosprezadas porque dão a impressão de serem falsas. }\end{array}$ \\
\hline 2. Efeito & $\begin{array}{l}\text { a) As mensagens afetam apenas àqueles que se preocupam com os riscos à } \\
\text { saúde. } \\
\text { b) Imagens que envolvem crianças são as que mais impressionam. } \\
\text { c) Imagens que mostram doenças como o câncer preocupam mais os fumantes. }\end{array}$ \\
\hline 3. Tipos de argumentos & $\begin{array}{l}\text { a) Os apelos visuais não são eficientes para inibir o ato de fumar. } \\
\text { b) As campanhas com imagens são apelativas e pouco informativas. } \\
\text { c) O fumante não tem medo das advertências. }\end{array}$ \\
\hline
\end{tabular}

Figura 5 - Categorias de percepção sobre as mensagens antitabagismo em embalagens de cigarro

Fonte: Elaborado pelos autores.

Quanto ao comportamento dos entrevistados frente às imagens, pode-se afirmar que embora conscientes de que o ato de fumar traz riscos à saúde os entrevistados mostraram fortes indícios de que preferem ignorar as mensagens de advertência, fato que é relatado na seguinte fala: "prefiro não olhar porque são feias" (universitário, 25 anos). As imagens são ignoradas pela metade dos entrevistados que preferem não olhá-las nas embalagens de cigarro. Alguns disseram, inclusive, que costumam colocar cartões para escondêlas. Essa reação é sustentada pelas afirmações de De Bruin (2006) o qual salienta que quando a ameaça contida em uma mensagem com apelo ao medo é muito forte, as pessoas ficam tão afetadas e incomodadas que as evitam ou ignoram como uma forma de autodefesa e se opõe as afirmações de que campanhas antitabagismo com mensagens carregadas de intensidade emocional têm maior eficácia que aquelas sem o mesmo apelo (Biener et al, 2004; Biener et al, 2008).

Entre aqueles que encaram e analisam a imagem há os que o fazem para menosprezar a campanha, conforme consta na afirmação de uma entrevistada: "eu olho e me dou conta do quão falso são essas imagens" (universitária, 23 anos). Esse relato encontra respaldo nas afirmações de Ramuski (2009) quando afirma que poucas imagens fazem referência ao universo jovem, o que dificulta a memorização das imagens e do impacto das campanhas.

Outro indício de que o comportamento é de ignorância e menosprezo às imagens ficou demonstrado, pelo fato de que parte dos entrevistados afirmou nunca comentar com outras pessoas sobre esse assunto e, aqueles que comentam o fazem por deboche, conforme se constata: “às vezes comento brincando, principalmente com aquela da impotência" (homem, 49 anos). Ressalta-se que o grau de envolvimento do indivíduo com o tema faz com que ele seja mais ou menos favorável a um determinado assunto, conforme exposto por Maheswaran e Meyers-Levy (1990). Portanto, entende-se que os fumantes que menosprezam as mensagens nas embalagens de cigarro podem ter um baixo envolvimento com o tema não levando em conta os riscos que o cigarro oferece para a saúde. A percepção dos fumantes é extremamente afetada pelo seu grau de envolvimento com o tema, ou seja, aqueles que possuem maior envolvimento com o tema acabam tendo uma percepção favorável à mensagem de apelo ao medo, enquanto aqueles que possuem baixo envolvimento com o tema tendem a ter uma percepção desfavorável a mensagem de apelo ao medo, simplesmente ignorando as mensagens.

Quanto ao efeito das imagens sobre os entrevistados, as categorias revelam que os fumantes mais interessados em assuntos relacionados à saúde são mais propensos a serem afetados pelas mensagens nas embalagens de cigarro conforme se observa nas palavras de um dos entrevistados que respondeu "elas tanto me fazem pensar, que estou gradativamente parando de fumar" (técnico em telecomunicações, 49 anos). Mais uma vez, ressalta-se a importância do grau de envolvimento do indivíduo com o tema abordado. Aqui, percebese que os fumantes que possuem maior consciência quanto aos malefícios do cigarro são mais afetados pelas mensagens. Esse achado vai ao encontro do que afirma Maheswaran e Meyers-Levy (1990) que indivíduos que possuem alto grau de envolvimento com o tema tendem a ser mais favoráveis às mensagens e, consequentemente, tendem a buscar um comportamento social adequado. Quanto ao apelo emocional e seu efeito nos entrevistados observou-se que as mensagens cujas imagens envolvem crianças causam maior impacto. A imagem que mostra um feto abortado em meio a restos de cigarro foi apontada por todos os respondentes como sendo a mais impressionante.

Apenas um dos entrevistados mostrou preocupação com o efeito do consumo do cigarro resultar em impotência sexual. As narrativas dos entrevistados evidenciaram que o tema que mais preocupa os fumantes são as doenças relacionadas ao câncer.

Quanto aos tipos de argumentos para convencer o fumante a parar de fumar, mais da metade dos entrevistados disse não acreditar na eficiência do apelo emocional relacionado ao medo sobre a decisão de parar de fumar. A transcrição da resposta de um dos fumantes quanto à tentativa de se utilizar o medo como apelo emocional evidencia o que a maioria pensa das campanhas com advertência antitabagismo por meio do uso de imagens sanitárias: “Eu acho esta campanha muito apelativa e pouco informativa. Se a pessoa para de fumar por medo, assim que ela esquecer o medo ela voltará a fumar. Acredito que alguém só para de fumar definitivamente se cria consciência dos benefícios reais de levar uma vida mais saudável" (universitário, 23 anos).

A maioria dos entrevistados disse acreditar que campanhas com mensagens que ressaltem os benefícios para parar de fumar seriam mais eficazes. Este pensamento é representado pelas seguintes palavras: “as pessoas iriam realmente olhar as imagens, pois as chocantes a gente esconde" (dona de casa, 47 anos) [...] 
Impacto do apelo ao medo nas embalagens do cigarro: a percepção de fumantes em relação às mensagens de advertência antitabagismo

“isto daria mais resultado que campanhas que tentam amedrontar, por que o fumante não tem medo das advertências" (autônomo, 47 anos).

De Bruin (2006) reforça a existência de uma linha de pensamento que entende que o apelo ao medo moderado parece ser mais efetivo para a mudança de comportamento, de forma que um apelo fraco pode não surtir resultado, enquanto um apelo forte pode ser tão apavorante ao receptor que o leva a evitá-lo ou ignorálo. Nas afirmações dos entrevistados, acima, fica evidente o menosprezo de significativa parte dos participantes às mensagens com uso do forte apelo ao medo.

Alguns entrevistados afirmaram que tanto campanhas que ressaltassem os benefícios de uma vida saudável, sem o fumo, quanto campanhas com advertências antitabagismo por meio de imagens deveriam ocorrer simultaneamente para que todos os fumantes fossem atingidos de uma forma ou de outra. A transcrição da fala de um entrevistado reflete essa opinião: "deveria ter as duas formas de campanhas, quanto mais opções de argumentos houver para convencer as pessoas a pararem de fumar melhor" (autônomo, 25 anos).

É importante reforçar que Renovato et al. (2009) enfatiza que campanhas sanitárias em embalagens de cigarros são completas e abrangentes, podendo ser, portanto, enviesadas. Pelas respostas dos entrevistados, percebe-se que há viés na utilização das mensagens, uma vez que em grande parte dos casos, a mensagem não atinge um de seus objetivos que é persuadir o fumante a parar de fumar, apesar de Hammond (2008) enfatizar que as advertências nos maços de cigarro estão entre as comunicações para a saúde com maior eficiência e maior custo-benefício.

Para os entrevistados mensagens com testemunho de não fumantes famosos podem servir de incentivo para potenciais fumantes. Nesse caso quase todos os entrevistados acreditam que seria muito positiva a participação de personalidades para influenciar os jovens, conforme pode ser depreendido da narrativa a seguir: "o cigarro era associado a pessoas famosas. Assim, quem fumava tinha status... e era chique... e isso influenciava as pessoas a começarem a fumar. Da mesma forma, essas personalidades poderiam contribuir para diminuir o uso do cigarro hoje em dia" (assistente, 40 anos).

A tendência em preferir uma campanha que apresente os benefícios de parar de fumar reforça os resultados de pesquisas anteriores que revelaram que as mensagens são mais eficientes quando buscam produzir um conjunto de mensagens positivas para um comportamento desejado (Strahan et al, 2002). Também é importante ressaltar a necessidade de focalizar as percepções relevantes para cada público alvo (Strahan et al, 2002), já que diferentes mensagens são compreendidas de forma específica por cada segmento da população.

Reforça-se ainda a importância da abordagem comportamental do Marketing Social que permite sua aplicação para promoção de causas sociais e políticas públicas (Walsh, Rudd, Moeykens \& Moloney, 1993), sendo frequentemente aplicado em casos de promoção à saúde e prevenção de doenças (Ling et al, 1992; Winett, 1995). Ao ser aplicado junto aos determinantes de um comportamento social de risco à saúde das pessoas, criam-se contextos de intervenção que podem auxiliar em campanhas de política pública da área (Hoek \& Jones, 2011). Dessa forma, ações de Marketing Social auxiliam no planejamento, foco, refinamento e implantação de programas sociais no âmbito da saúde, além de servir como contra-argumentação para iniciativas publicitárias das organizações utilitaristas que podem trazer consequências pouco saudáveis (Petersen, 2008).

Deve-se ainda focalizar as percepções relevantes para cada público alvo, pois segundo Strahan et al. (2002) isso é essencial, já que diferentes mensagens são compreendidas de forma específica por cada segmento da população, por exemplo, aqueles que fumam versus aqueles que estão na iminência de fumar; adolescentes versus adultos.

\section{Conclusões e Discussões Finais}

Nesse estudo em que se objetivou identificar a percepção de fumantes em relação às imagens antitabagismo nas embalagens de cigarro, verificando como a exposição dessas imagens tem efeito sobre a experiência do fumante apresentou reações diferenciadas em relação ao impacto causado pelas imagens de advertência. Essa constatação evidencia a necessidade de elaboração de campanhas adequadas para o perfil dos diferentes públicos. A mesma campanha aplicada para diferentes nichos trazem diferentes percepções e resultados de persuasão, havendo assim, oportunidades para maior eficácia das campanhas se tratadas de forma diferenciada em cada grupo social.

A análise inferencial das opiniões permitiu o agrupamento das respostas em três dimensões analíticas, comportamento, efeito e tipos de argumentos, que resultaram em nove categorias relativas à percepção dos entrevistados quanto às imagens sanitárias em campanhas antitabagismo. As categorias capturadas podem ser descritas como: 1) o ato de fumar traz riscos à saúde; 2) As mensagens antitabagismo são ignoradas porque os fumantes preferem não olhá-las; 3) As imagens sanitárias são menosprezadas porque dão a impressão de serem falsas; 4) As mensagens afetam apenas àqueles que se preocupam com os riscos à saúde; 5) Imagens que envolvem crianças são as que mais impressionam; 6) Imagens que mostram doenças como os cânceres preocupam mais os fumantes; 7) Os apelos visuais não são eficientes para inibir o ato de fumar; 8) As campanhas com imagens são apelativas e pouco informativas; 9) O fumante não tem medo das advertências. 
Verificou-se, portanto, que as pessoas mais interessadas em assuntos relacionados à saúde, ou seja, com alto grau de envolvimento sobre o tema, são mais propensas a serem afetadas pelas imagens porque têm maior familiaridade e compreensão sobre os riscos de saúde que incorrem os fumantes.

Confirmou-se, ainda, que as advertências que pretendem por meio do apelo emocional do medo influenciar no hábito de fumar, não impactam ou interferem na decisão do fumante, visto que esse prefere ignorar as imagens não as olhando e quando as olha o teor apelativo tem efeito contrário em suas decisões. Por considerar as imagens apelativas não dão a importância a todos os malefícios que o cigarro provoca e, por isso, os apelos visuais não se tornam inibidores e não provocam medo, fato que deve ser considerado em campanhas antifumígeras, uma vez que os fumantes entrevistados nesse estudo tenderam a rejeitar e ignorar as imagens que fazem apelo ao medo.

Outra conclusão que se aponta é que campanhas que ressaltassem os benefícios de não fumar poderiam desestimular as ações dos fumantes e, por isso, se fossem inseridos nas campanhas antitabagismo, relatos de experiências positivos a percepção dos fumantes e o impacto sobre sua decisão de fumar poderia ser diferente, visto que as mensagens que apresentam benefícios para parar de fumar parecem ter relações positivas com a rejeição ao cigarro. Na percepção dos entrevistados mensagens endossadas por celebridades que não fumam, serviria de maior inspiração para o estímulo à decisão de parar de fumar.

O Marketing Social deve ser usado diversificando-se as mensagens para que aja uma maior persuasão nos consumidores levando-se em consideração que pessoas com grau de envolvimento diferenciado terão reações díspares aos mais diversos tipos de mensagens. Por isso, como as pessoas são diferentes e possuem grau de envolvimento não iguais, elas necessitam de mensagens diferentes, pois cada um percebem a mensagem de forma particular. Adicionalmente, ainda que existam diferentes percepções e receptividade das campanhas de marketing social, os resultados aqui apresentados corroboram estudos (e.g. Sorensen, Jenkins, Emmelin, Stenlund, Weinehall, Earle-Richardson e May, 2011) que apontam o uso do marketing social como estratégia possível para se incentivar em algum grau comportamentos mais seguros por parte dos indivíduos.

\subsection{Limitações e Recomendações para Estudos Futuros}

Inicialmente, deve-se considerar que o presente estudo é baseado numa amostra de fumantes, o que é importante e relevante para a construção de teorias sobre a realidade social, entretanto, isso não garante que os resultados aqui levantados possam ser generalizados. Eles representam situações específicas que não necessariamente representam a realidade por completo.

Campanhas de saúde pública locais tendem a ser mais efetivas que aquelas de âmbito nacional, denotando que as características de uma população divergem em função do contexto. Assim sendo, como a realidade estudada é também específica de uma localidade, dado que os respondentes estão circunscritos a uma mesma região, local onde o estudo foi realizado, com características sociodemográficas semelhantes, isso limita que os resultados sejam generalizados ou mesmo replicados para outros contextos sem as devidas adaptações e considerações locais. Sugere-se diante disso, inclusive, que esse estudo seja estendido para outras localidades, a fim de se estabelecer comparações entre o comportamento, efeito e tipos de argumentos percebidos como resultantes dessas campanhas em diferentes culturas.

Ademais o presente estudo teve como amostra apenas pessoas que fumam. Existe outro grupo de pessoas não abordadas, os não fumantes, que também têm suas percepções relativas à eficácia das campanhas antifumo. Por isso, dada a limitação do presente estudo, que analisou apenas a percepção dos fumantes, recomenda-se ampliar o escopo do estudo para os não fumantes. Dessa forma, poder-se-ia comparar as percepções dessas iniciativas em relação a ambos os grupos - fumantes e não fumantes.

Por fim, ainda que essas iniciativas das políticas públicas para o combate ao tabagismo não sejam o foco do presente estudo, não se pode menosprezá-las ou julgá-las irrelevantes nessa discussão. É importante entender a integração das diferentes iniciativas que visam um mesmo resultado. Por isso, um passo posterior a essa pesquisa poderia ser o estudo das diferentes campanhas antitabagismo ao longo do período a partir do qual as mesmas foram instituídas.

\section{Referências}

ALETP. Novas imagens de advertências para maços de cigarro. 2008. Disponível em: <http://aletp.com/2008/05/27/novas-imagens-de-advertencias-para-macos-de-cigarro/>. Acesso em: 21 Jul. 2011.

Andreasen, A. R. (1994). Social marketing: its definition and domain. Journal of Public Policy \& Marketing, 13(1), 108-114.

Andreasen, A. R. (1995). Marketing social change: changing behavior to promote health, social development and the environment. San Francisco: Jossey-Bass.

Andreasen, A. R. (2002) Marketing Social Marketing in the Social Change Marketplace Journal of Public Policy \& Marketing, 21, 3-13. 
Impacto do apelo ao medo nas embalagens do cigarro: a percepção de fumantes em relação às mensagens de advertência antitabagismo

Balbach, E. D., \& Glantz, S. A. (1998). Tobacco control advocates must demand high-quality media campaigns: the California experience. Tobacco Control, 7, 397-408.

Bardin, L. (1997). Análise de conteúdo. Lisboa: Edições 70.

Belch, M. A. A. (1982). Segmentation strategy for the 1980's: profiling the socially-concerned market through lifestyle analysis. Journal of the Academy of Marketing Science, 10(Fall), 345-359.

Biener, L., Ji, M., Gilpin, E. A., \& Albers, A. B. (2004). The impact of emotional tone, message, and broadcast parameters in youth anti-smoking advertisements. Journal of Health Communications, 9(3), $259-274$.

Biener, L., Wakefield, M., Shiner, C. M., \& Siegel, M. (2008). How broadcast volume and emotional content affect youth recall of anti-tobacco advertising. American Journal of Preventive Medicine, 35(1), 14-19.

Brasil. Lei no 9.294 de 15 de ju/ho de 1996. Dispõe sobre as restrições ao uso e à propaganda de produtos fumígeros, bebidas alcoólicas, medicamentos, terapias e defensivos agrícolas, nos termos do $\S 4^{\circ}$ do art. 220 da Constituição Federal. Disponível em: <http://www.planalto.gov.br/ccivil_03/Leis/L9294.htm>. Acesso em: 2 set. 2011.

Cavalcante, T. M. (2007). O controle do tabagismo no Brasil: avanços e desafios. Revista de Psiquiatria Clínica, 32(5), 283-300.

Cotter, T., Perez, D., Dunlop, S., Hung, W. T., Dessaix, A., \& Bishop, J. F. (2010). The case of recycling and adapting anti-tobacco mass media campaign. Tobacco Control, 19(6), 514-517.

De Bruin, L. M. (2006). Cigarette smokers' perceptions of fear-appeal advertising. Dissertação (Mestrado em Research Psychology). Department of Psychology. Faculty of Humanities at the University of Pretoria.

Farrelly, M. C., Davis, K. C., Duke, J., \& Messeri, P. (2009). Sustaining 'truth': changes in youth tobacco attitudes and smoking intentions after 3 years of a national antismoking campaign. Health Education Research, 24(1), 4248.

Fontes, M. (2008). Marketing social. Novos paradigmas. Rio de Janeiro: Elsevier.

Gallopel-Morvan, K., Gabriel, P., Gall-Ely, M., Rieunier, S., \& Urien, B. (2011). The use of visual warnings in social marketing: the case of tobacco. Journal of Business Research, 64(1), 7-11.

Hammond, D. (2008). Health warnings on tobacco packages: summary of evidence and legal challenges. Department of Health Studies, University of Waterloo.

Hassan, L. M., Walsh, G., Shiu, E. K., Hastings, G., \& Harris, F. (2007). Molding persuasion in social advertising. Journal of Advertising, 36(Summer), 13-28.

Hastings, G., Stead, M., \& Webb, J. (2004). Fear appeals in social marketing: strategies and ethical reasons for concern. Psychology \& Marketing, 21(11), 961-986.

Hoek, J., \& Jones, S. C. (2011). Regulation, public health and social marketing: a behavior change trinity. Journal of Social Marketing, 1(1), 32-44.

Hoek, J., Wong, C., Gendall, P., Louviere, J., \& Cong, K. (2011). Effects of dissuasive packaging on young adult smokers. Tobacco Control, 20(3), 183-188.

Iglesias, R., Jha, P., Pinto, M., Silva, V. L. C., \& Godinho, J. (2007). Controle do tabagismo no Brasil. Documento de discussão - Saúde, Nutrição e População (HNP). Disponível em: <http://siteresources.worldbank.org/HEALTHNUTRITIONANDPOPULATION/Resources/281627-

1095698140167/BrazilTobaccoControlFinal.pdf>. Acesso em: 21 ago. 2008.

Instituto Brasileiro de Geografia e Estatística (IBGE). (2008). Pesquisa Nacional de Amostra por Domicílio PNAD . Tabagismo. Disponível

<http://www.ibge.gov.br/home/presidencia/noticias/noticia_visualiza.php?id_noticia=1505\&id_pagina=1>.

Acesso em: 21 jul. 2011.

Instituto Nacional de Câncer - INCA. (2003). Programa Nacional de Controle do Tabagismo e outros fatores de risco de câncer. 2.ed. Disponível em: <http://www.inca.gov.br/tabagismo/frameset.asp?item=programa\&link=programa_de_tabagismo.pdf>. Acesso em: 02 set. 2011.

Kotler, P., Zaltman, G. (1971). Social marketing: an approach to planned social change. Journal of Marketing, 35(July), 3-12.

La Tour, M. S., \& Rotfeld, H. J. (1997). There are threats and (maybe) fear-caused arousal: theory and confusions of appeals to fear and fear arousal itself. Journal of Advertising, 26(3), 45-59.

Lefebvre, R. C., \& Flora, J. A. (1988). Social marketing and public health intervention. Health Education Quarterly, 15(3), 299-315. 
Ling, J. C., Franklin, B. A. K., Lindsteadt, J. F., \& Gearon, S. A. N. (1992). Social marketing: its place in public health. Annual Review of Public Health, 13, 341-362.

MacKay, J., \& Crofton, J. (1996). Tobacco and the developing world. British Medical Bulletin, 52(1), 206-221.

Mackay, J., \& Eriksen, M. (2002). The tobacco atlas. Brighton: World Health Organization.

Maheswaran, D., \& Meyers-Levy J. (1990). The influence on message framing and issue involvement. Journal of Marketing Research 27, 361-367.

Malone, R. E., Grundy, Q., \& Bero, L. A. (2012). Tobacco industry denormalisation as a tobacco intervention: a review. Tobacco Control, 21(2), 162-170.

Manoff, R. K. (1985). Social marketing: new imperative for public health. New York: Praeger Publishing.

Martins, G. A., \& Theóphilo, C. R. (2007). Metodologia da investigação científica para ciências sociais aplicadas. São Paulo: Atlas.

Milne, S., Sheeran, P., \& Orbell, S. (2000). Prediction and intervention in health-related behavior: a meta-analytic review of protection motivation theory. Journal of Applied Social Psychology, 30(1), 106-143.

O'Connor, L., \& Lundstrom, K. (2011). The impact of social marketing strategies on the information seeking behaviors of college students. Reference \& User Services Quarterly, 50(4), 351-365.

Peattie, K., \& Peattie, S. (2009). Social marketing: a pathway to consumption reduction? Journal of Business Research, 62(2), 260-268.

Pelsmacker, P., Cauberghe, V., \& Dens, N. (2011). Fear appeal effectiveness for familiar and unfamiliar issues. journal of Social Marketing, 1(3), 171-191.

Petersen, J. (2008). Social marketing and public health. (Doutorado em Marketing). Department of Geography. University College London.

Ramuski, C. L. (2009). Impactos da campanha antitabagista veiculada em carteiras de cigarro junto aos jovens fumantes. Pensamento \& Realidade, 24(1), 11-32.

Rea, L. M., \& Parker, R. A. (2000). Metodologia de Pesquisa: do planejamento à execução. São Paulo: Pioneira.

Renovato, R. D., Bagnato, M. H. S., Missio, L., Murback, S. E. S. L., Cruz, L. P., \& Bassinello, G. A. H. (2009). Significados e sentidos de saúde socializados por artefatos culturais: leituras das imagens de advertência nos maços de cigarros. Ciência \& Saúde Coletiva, 14(1), 1599-1608.

Rodgers, R. W. (1983). Cognitive and physiological processes in fear-appeals and attitude change: A revised theory of protection motivation. In J. Cacioppo \& R. Petty (orgs.). Social psychophysiology. Guilford: New York.

Ruas, E. C. M., \& Estellita-Lins, C. (2011). Imagens de advertências impressas nos maços de cigarros brasileiros: a busca da anti-propaganda. Intercom - Sociedade Brasileira de Estudos Interdisciplinares da Comunicação. Anais... XXXIV Congresso Brasileiro de Ciências da Comunicação. Recife, 34.

Sabbane, L. I., Lowrey, T. M., \& Chebat, J. C. (2009). The effectiveness of cigarette warning label threats on nonsmoking adolescents. Journal of Consumer Affairs, 43(2), 332-345.

Salla, F. (2011). Quem define as classes sociais no Brasil? Disponivel em: <http://mundoestranho.abril.com.br/materia/quem-define-as-classes-sociais-no-brasil-geografia >. Acesso em 12 jul. 2012.

Santos, J. D. P. (2011). Avaliação da efetividade do programa de tratamento do tabagismo no Sistema Único de Saúde. 2011. 87 f. Dissertação (Mestrado em Epidemiologia). Faculdade de Medicina. Universidade Federal do Rio Grande do Sul. Rio Grande do Sul.

Shapiro, S. J., Perreault, W. D., \& McCarthy, E. J. (1999). Basic marketing: a global managerial approach. Toronto: McGraw Hill.

Shehryar, O., \& Hunt, M. A. A terror management perspective on the persuasiveness of fear appeals. (2005). Journal of Consumer Psychology, 15(4), 275-287.

Sorensen, J. A., Jenkins, P. L., Emmelin, M., Stenlund, H., Weinehall, L., Earle-Richardosn, G. B., \& May, J. J. (2011). The social marketing of safety behviors: a quasi-randomized controlled trial od tractor retrofitting incentives. American Journal of Public Health, 101(4), 678-684.

Souza, E. L., \& Dias, E. M. (2011). Benefícios ambientais e em saúde da lei paulista antifumo - Lei Estadual 13.541/09. Revista Internacional de Direito e Cidadania, 10, 55-61.

Spink, M. J. (1998). Desvendando as teorias implícitas: uma metodologia de análise das Representações Sociais. In P. Guareschi \& S. Jovchelovitch (orgs.). Textos em representações sociais. (4a ed.). Petrópolis: Vozes. 
Spink, M. J. P., Lisboa, M. S., \& Ribeiro, F. R. G. (2009). A construção do tabagismo como problema de Saúde Pública: uma confluência entre interesses políticos e processo de legitimação científica. Interface, 13(29), 353365.

Strahan, E. J., White, K., Fong, G. T., Fabrigar, L. R., Zanna, M. P., \& Cameron, R. (2002). Enhancing the effectiveness of tobacco package warning labels: a social psychological perspective. Waterloo: Department of Psychology. University of Waterloo.

Tangari, A. H., Burton, S., Andrews, J. C., \& Netmeyer, R. G. (2007). How do antitobacco campaign advertising and smoking status affect beliefs and intentions? Some similarities and differences between adults and adolescents. Journal of Public Policy \& Marketing, 26(1), 60-74.

Taylor, S. J., \& Bogdan. R. (1998). Introduction to qualitative research methods. New York: John Wiley \& Sons.

Terry-McElrath, Y. M., Emery, S., Wakefield, M. A., O’Malley, P. M., Szczypka, G., \& Johnston, L. D. (2011). Effects of tobacco-related media campaigns on smoking along 20-30-year-old adults: longitudinal data from USA. Tobacco Control, 22(1), 38-45.

Toledo, L. A., \& Caigawa, S. M. (2003). Marketing Social e Comportamento do Consumidor. Disponível em: <http://www.portaldomarketing.com.br/Artigos/Marketing\%20social\%20e\%20comportamento\%20do\%20consu midor.htm>. Acesso em: 12 fev. 2012.

Wakefield, M. A. (2011). Welcome to cardboard country: how plain packaging change the subjective experience of smoking. Tobacco Control, 20(5), 321-322.

Wakefield, M. A., Durkin, S.; Spitall, M. J., Siahpush, M., Scollo, M., Simpson, J. A., Chapman, S., White, V., \& Hill, D. (2008). Impact of tobacco control policies and mass media campaigns on monthly adult smoking prevalence. American Journal of Public Health, 98(8), 1443-1450.

Walsh, D. C., Rudd, R. E., Moeykens, B. A., \& Moloney, T. W. (1993). Social marketing for public health. Health Affairs, 12(2), 104-119.

Wiebe, G. D. (1952). Merchandising commodities and citizenship on television. Public Opinion Quarterly, 15(Winter), 679-691.

Winett, R. A. (1995). A framework for health promotion and disease prevention programs. American Psychologist, 50(5), 341-350.

World Bank. (1999). Curbing the epidemic. Governments and the economics of tobacco control.

World Health Organization. (2011). Tobacco. Fact sheet no 339. Disponível em:

<http://www.who.int/mediacentre/factsheets/fs339/en/index.html>. Acesso em: 29 fev. 2012. 